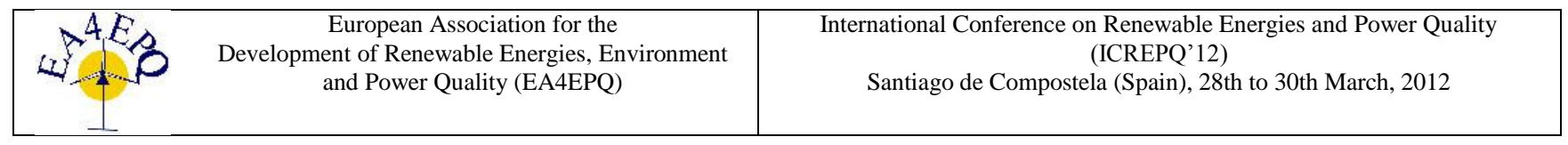

\title{
Development of Energy Saving Mechanism for Renewable Hydrogen Vehicles
}

\author{
K.K.T. Thanapalan ${ }^{1,2}$, F. Zhang ${ }^{2}$, A.D. Procter ${ }^{2}$, S.J.W. Carr ${ }^{2}$, G.C. Premier ${ }^{1,2}$ A.J. Guwy ${ }^{2}$ and J. Maddy ${ }^{2}$ \\ ${ }^{1}$ Sustainable Environment Research Centre (SERC) \\ Faculty of Advanced Technology \\ University of Glamorgan \\ Pontypridd CF37 1DL, UK \\ Phone/Fax number: +0044 1443 654294, e-mail: kthanapa@glam.ac.uk \\ ${ }^{2}$ Sustainable Environment Research Centre (SERC) \\ Renewable Hydrogen Research \& Demonstration Centre \\ University of Glamorgan \\ Baglan Energy Park, Baglan \\ Port Talbot SA12 7AX, UK \\ Phone/Fax number: +0044 1639814510
}

\begin{abstract}
This paper describes the development of energy saving mechanisms for renewable hydrogen vehicles, thereby providing extended range and improved efficiency. Simulation studies of configuration setup and analysis for better energy management strategies are carried out using simulation tools developed by the University of Glamorgan (UoG), Faculty of Advanced Technology (FAT). The simulation tools are used to analyze the effect of operating conditions and energy demand of a hybrid vehicle. A dynamic model of onboard hydrogen production employing electrolysis energized by electricity recovered from the vehicle's suspension sub-system, is implemented in MATLAB/Simulink ${ }^{\mathrm{TM}}$ and integrated with a fuel cell vehicle model. The entire system model is then parameterized to represent a renewable hydrogen fuel cell vehicle for simulation analyses. Simulation results show that by using recovered energy normally lost in damping, appreciable benefits might be accrued from hydrogen production on-board.
\end{abstract}

\section{Key words}

Powertrain, Energy saving, Energy sources, Renewable hydrogen vehicles, System modelling

\section{Nomenclature}

$b_{t} \quad$ tire damping coefficient $\left(\mathrm{Nm}^{-1}\right)$

$b_{s} \quad$ damper coefficient $\left(\mathrm{Nm}^{-1}\right)$

$F_{f} \quad$ frictional force $(N)$

$F_{A} \quad$ applied force $(N)$
$F_{a} \quad$ applied force (active component) $(N)$

$F_{p} \quad$ applied force (passive component) $(N)$

$\Delta H \quad$ change in enthalpy $\left(k_{J} \mathrm{~mol}^{-1}\right)$

$i \quad$ current (Amp)

$i_{\text {Loss }} \quad$ internal current loss (Amp)

$k_{s} \quad$ spring stiffness $\left(\mathrm{Nm}^{-1}\right)$

$k_{t} \quad$ tire stiffness $\left(\mathrm{Nm}^{-1}\right)$

$m_{s} \quad$ mass of a vehicle (quarter) $(\mathrm{kg})$

$m_{u} \quad$ mass of a wheel (components) $(\mathrm{kg})$

$\eta_{F} \quad$ faraday efficiency

$\Delta S \quad$ change in entropy $\left(k J m^{\prime} l^{-1}\right)$

$T$ temperature $(K)$

$z_{s} \quad$ displacement of the vehicle body $(m)$

$z_{u} \quad$ displacement of the suspension system $(m)$

$z_{r} \quad$ displacement of the road disturbance $(m)$

$H_{2}$ hydrogen

$\mathrm{O}_{2} \quad$ oxygen

$\mathrm{H}_{2} \mathrm{O}$ water

\section{Introduction}

The need to reduce carbon emissions from the transport sector has gained considerable attention during the last few decades. The UK government has targets for a 
reduction in $\mathrm{CO}_{2}$ emissions of $80 \%$ by 2050 . The alternative energy carrier of hydrogen and hydrogen fuel cell vehicles have their part to play in meeting these targets. Whilst incremental improvements are being made with vehicles powered by traditional fossil fuels, hydrogen provides a good opportunity to significantly reduce carbon emissions, whilst maintaining the travel range of vehicles. The transport sector has the fastest growing demand for energy, yet it is currently almost entirely dependent on fossil fuels [1]. Increasing global demand for fuels and depleting global oil resources inevitably leads to an increase in the cost of these fossil fuels. Renewably produced hydrogen, accessible from a number of production routes with no carbon emissions is an ultimate target. Research and development have a fundamental role to play in addressing issues that are acting as a barrier to the accelerated deployment of this energy technology. To this end, research and development is carried out to investigate and improve the performance, stability and reliability of the fuel cell based hybrid electric vehicle system, see for example [2], [3], and [4]. The complexity of the system requires elaborate and innovative studies for proper configuration, component sizing and control system development to fully explore the potential of this advanced technology. A hybrid Fuel Cell (FC) vehicle contains an energy storage system to provide peak power and capture energy [5]. This usually is a battery or an ultracapacitor pack or a combination of both. Recent studies [2], [6] have shown that the combined battery-ultracapacitor energy storage system can provide better performance and fuel economy.

In this paper, developments of energy saving mechanism for hydrogen vehicles are developed for performance improvements. Essentially and in general terms there are two approaches to energy saving mechanisms; implementation of a better energy management system by providing optimal powertrain topologies for the energy sources and incorporating an energy recovery mechanism. This work addresses both approaches by presenting a powertrain topology for hybrid electric vehicles (HEV) for better energy management and development of an onboard hydrogen production and storage system for energy recovery. Analyses are carried out using simulation tools developed by the UoG. This paper begins with a discussion of hydrogen generation techniques, in particular the progress of renewable hydrogen production with reference to the work of the University of Glamorgan's Sustainable Environment Research Centre (SERC) and followed by the simulation model of the onboard hydrogen production mechanism and analyses.

\section{Hydrogen Generation Techniques}

UK energy production and consumption for the period of 1970 to 2009 are shown in Figure. 1 Hydrogen as an energy carrier is of considerable relevance in such circumstances, primarily because it may be produced from several renewable resources, through a number of technological routes [2]. Hydrogen produced from renewable sources has the flexibility to be used as a clean, safe and convenient transport fuel.

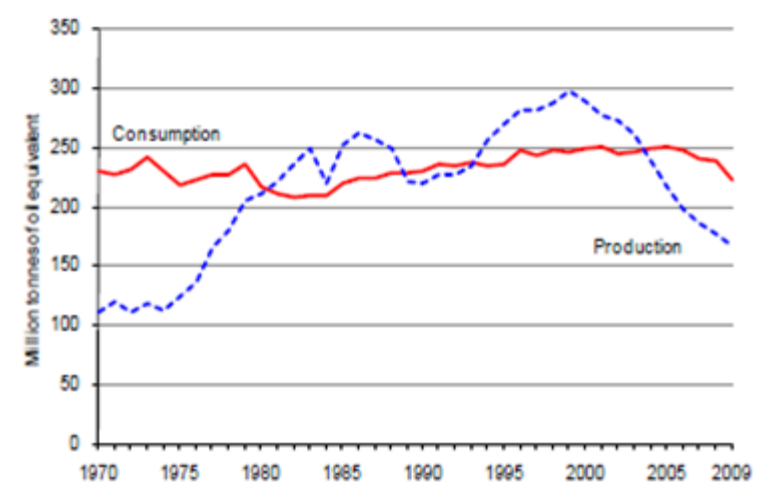

Fig.1. UK energy production and consumption 1970 to 2009 [7]

From Figure. 1 it is clear that the energy consumption is growing while production is decreasing. Energy shortage would be further exacerbated by fiscal and economic measures which may be required to mitigate green house gas (GHG) effects caused by burning fossil fuels. UNFCC-GHG inventory report shows that UK carbon emissions are significantly high (see Fig.2). In order to reduce carbon emissions, policy makers set some high targets to achieve. The current UK target against 1990 emissions is about $25 \%$ and $34 \%$ cut in emissions by 2020. Furthermore, $80 \%$ cut in emissions by 2050 is also targeted [8].

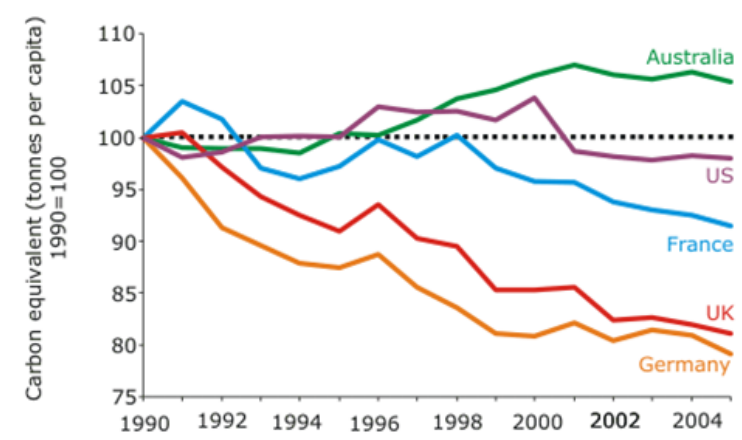

Fig.2. UNFCC green house gas (GHG) inventory

Work at the UoG's hydrogen Centre mainly focuses on the production of renewable hydrogen in the following methods: solar powered hydrogen production, optimising the electrolyser performance, wind power, and biohydrogen production from renewable biomass or waste. The principles of operations of the production of renewable hydrogen are illustrated in Figure. 3. The Baglan Hydrogen Centre has a $20 \mathrm{kWp}$ PV array, electrolyser with a capacity of $15 \mathrm{~m}^{3} h r^{-1}, 440$ bar hydrogen storage, $12 \mathrm{~kW}$ PEM fuel cell with additional battery storage, along with a hydrogen/CNG vehicle refuelling station. 


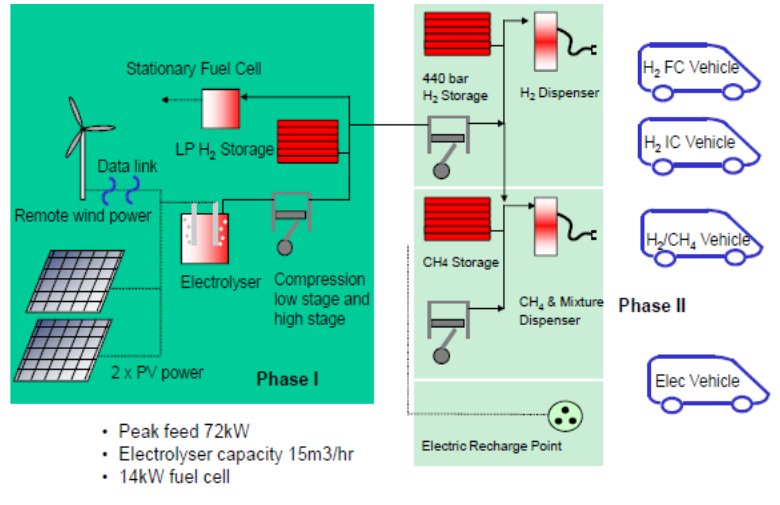

Figure.3. UoG Baglan Hydrogen Centre renewable hydrogen: Principles of operations

Biohydrogen production from renewable biomass or waste can be another option for on-site hydrogen generation. Hydrogen production by using fermentative bacteria can use various feedstock such as agricultural and food waste and therefore reduce waste treatment cost while simultaneously generate renewable hydrogen [9]. Two pilot scale biohydrogen reactors are being operated by the University of Glamorgan Sustainable Environment Research Centre: Aberystwyth two-stage pilot plant using crop (Figure 4a), and Barry biohydrogen plant using wheat feed (Figure.4b).

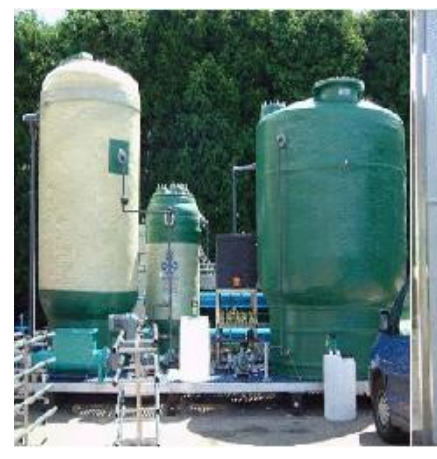

$\mathrm{a}$

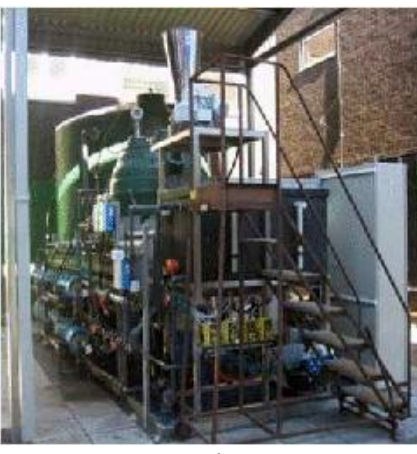

b
Figure.4. biohydrogen plants using crops and wheat feed

Performance optimisation of an electrolyser can be achieved by changing the electrolyser design, developing an optimal control methodology and combination with short term energy storage. Furthermore, by using a power source emulator, it will be possible to investigate the operation of different electrolyser technologies with various renewable sources. Optimizing the process efficiency of round trip hydrogen storage as well as hydrogen generation for vehicle use is currently being investigated. On-site hydrogen production is used to fuel/refuel our renewable hydrogen fuel cell vehicles [2]. In order to do that the UoG-SERC has developed the UK's first alternative energy refuelling facility at the University's Hydrogen Centre in Baglan, South Wales and a small refueller in Glyntaff campus (see Figure.5).

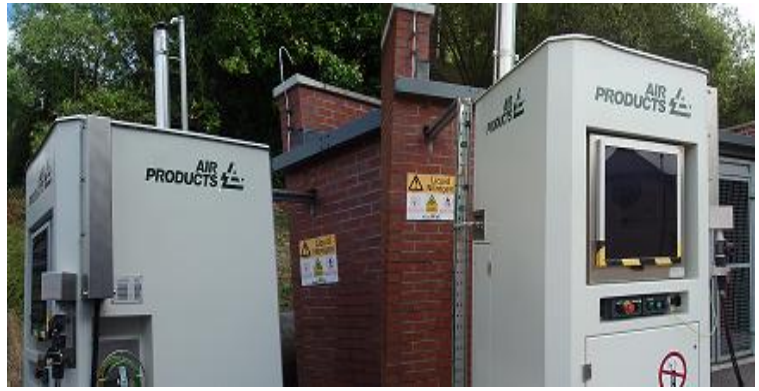

Figure.5. UoG hydrogen re-fuelling station

However it is important to note that the range and efficiencies can be improved by incorporating an onboard production mechanism to these vehicles. Development of such an on-board system is investigated in the next section.

\section{Simulation tools and hydrogen vehicles}

In the case of renewable hydrogen fuel cell vehicles, on-board hydrogen production is highly valued since it will leads to performance improvement. A typical dynamic model of an on-board hydrogen production mechanism contains two interacting subsystems: a generator and associated electrolyser and a fuel cell stack. In this paper, a PEM fuel cell system dynamic model described in [10] is adopted. A dynamic model of an electrolyser is presented below. The fuel cell and electrolyser models are then incorporated into a system with a suspension energy recovery mechanism, used in order to recover energy for subsequent hydrogen production on-board.

The purpose of a suspension system is to support the vehicle body and increase ride comfort. Currently, there are three different types of suspension systems used in automobile industry: passive, semi-active and active [11]. The traditional passive suspensions use springs and dampers to absorb the oscillation while in active ones the suspension is controlled by external controller. Semiactive suspensions include devices such as springs and shock absorbers together with other systems like hydro pneumatic and electromagnetic suspension. On the one hand, the use of semi-active/active suspension achieves a better isolation performance for various vibration modes and improves the ride comfort, but on the other, they increase the cost, weight and energy consumption of the car. The suspension energy recovery mechanism developed here is to recovery some energy from suspension system to improve the energy efficiency.

The dynamic model of one wheel suspension system can be expressed by differential equations [12] 


$$
\begin{aligned}
& m_{s} \ddot{z}_{s}=-k_{s}\left(z_{s}-z_{u}\right)-b_{s}\left(\dot{z}_{s}-\dot{z}_{u}\right) \\
& -F_{f}+F_{A} \\
& m_{u} \ddot{z}_{u}=k_{s}\left(z_{s}-z_{u}\right)+b_{s}\left(\dot{z}_{s}-\dot{z}_{u}\right) \\
& -k_{t}\left(z_{u}-z_{r}\right)-b_{t}\left(\dot{z}_{u}-\dot{z}_{r}\right)+F_{f}-F_{A}
\end{aligned}
$$

The frictional force can be calculated by

$$
\begin{aligned}
& \left|\dot{z}_{s}-\dot{z}_{u}\right|>0.01 \mathrm{~m} / \mathrm{s} \Rightarrow F_{f}=\mu \cdot \operatorname{sgn}\left(\dot{z}_{s}-\dot{z}_{u}\right) \\
& \left|\dot{z}_{s}-\dot{z}_{u}\right|<0.01 \mathrm{~m} / \mathrm{s} \Rightarrow F_{f}=\mu \cdot \sin \left(\frac{\dot{z}_{s}-\dot{z}_{u}}{0.01} \frac{\pi}{2}\right)
\end{aligned}
$$

The applied force is combined with both active and passive component, denotes as $F_{a}$ and $F_{p}$ respectively,

$$
F_{A}=F_{a}+F_{p}=-C \dot{z}_{s}-B\left(\dot{z}_{s}-\dot{z}_{u}\right)
$$

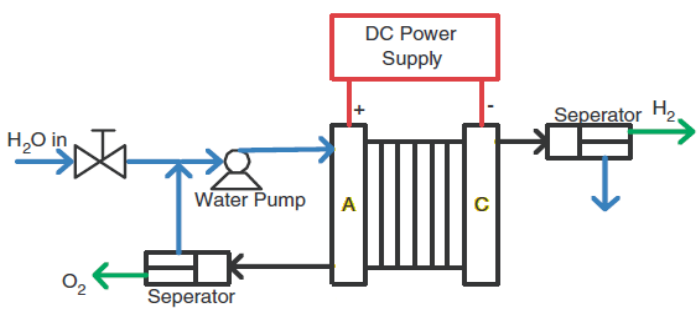

Figure.6. PEM electrolyzer [13]

An electrolyser (Figure.6.) utilises electrical current to decompose water into hydrogen and oxygen. The overall electrochemical reaction can be expressed by:

$$
\mathrm{H}_{2} \mathrm{O} \text { +electrical energy } \rightarrow \mathrm{H}_{2}+\frac{1}{2} \mathrm{O}_{2}
$$

By passing the electric current through anode and cathode electrodes, two reactions taking place, one at each of the electrodes:

$$
\text { Anode: } 2 \mathrm{H}_{2} \mathrm{O} \rightarrow \mathrm{O}_{2}+4 \mathrm{H}^{+}+4 e^{-}
$$

Cathode: $4 \mathrm{H}^{+}+4 e^{-} \rightarrow 2 \mathrm{H}_{2}$

Generally, it is assumed that: (a) hydrogen and oxygen are ideal gases, (b) water is an incompressible fluid, and (c) the gas and liquid phases are separate. Based on these assumptions the Gibbs energy $\Delta \mathrm{G}$ required for water splitting is expressed by:

$$
\Delta G=\Delta H-T \Delta S
$$

At standard laboratory conditions (defined here as $25^{\circ} \mathrm{C}$ and 1 bar), the Gibbs energy is $\Delta G_{o}=237 \mathrm{kJmol}^{-1}$. The Faraday efficiency $\eta_{F}$ is defined as the ratio between the actual and theoretical maximum amount of hydrogen produced in the electrolyser due to the fact that overpotential losses occur through ohmic, activation and mass transfer. Essentially, oxygen must transfer and be generated in molecular form at the cathode and hydrogen at the anode. An empirical expression [13], [14] that aggregates these phenomena for a given temperature is:

$$
\eta_{F}=\frac{i-i_{\text {Loss }}}{i}
$$

where $i$ is the electrolyser current density, $i_{\text {Loss }}$ i\$2 the internal current loss due to oxygen and hydrogen travel between anode and cathode. In general, this loss is very small, normally less than $1 \%$ of the operating current density. According to Faraday's law, the production rate of hydrogen in an electrolyser cell is directly proportional to the electrical current in the external circuit. Hence, the total hydrogen production rate in an electrolyser, which consists of several cells connected in series, can be expressed as:

$$
\dot{n}_{H_{2}}=\eta_{F} \frac{n_{c} I}{z F}
$$

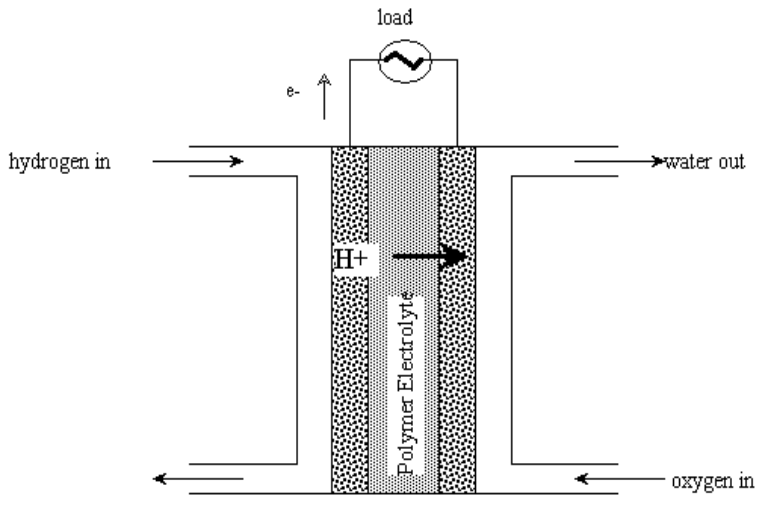

Fig.7. Basic principle of PEM fuel cell

A fuel cell (Fig.7.) is an electrochemical energy conversion device which converts the chemicals hydrogen and oxygen into water and in the process produces electricity. The overall electrochemical reactions can be expressed by:

$$
2 \mathrm{H}_{2}+\mathrm{O}_{2} \rightarrow 2 \mathrm{H}_{2} \mathrm{O}
$$

with

$$
\begin{aligned}
& \text { Anode }: 2 \mathrm{H}_{2} \rightarrow 4 \mathrm{H}^{+}+4 e^{-} \\
& \text {Cathode }: \mathrm{O}_{2}+4 \mathrm{H}^{+}+4 e^{-} \rightarrow 2 \mathrm{H}_{2} \mathrm{O}
\end{aligned}
$$




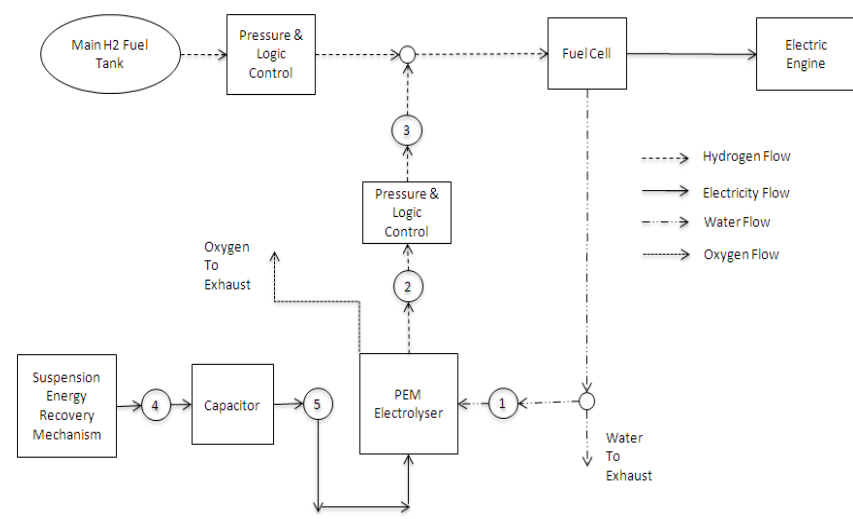

Figure. 8. On-board hydrogen production mechanism

This PEM fuel cell system model and the electrolyser model described above are now used for the development of the on-board hydrogen production mechanism model. A quantitative analysis based on simplicity, efficiency and cost was performed to determine the best powertrain topologies for use in this study. Figure. 8 shows the chosen topology. The suspension energy recovery system will recover some of the energy from the active suspension actuator. The recovered energy will drive the electrolyser to produce hydrogen in addition to stored hydrogen fuel. Because the energy recovered from active suspension will be relatively small hence the hydrogen produced will be limited, therefore, it is not necessary to compress the hydrogen produced to the fuel tank. This subsystem model is implemented in MATLAB/Simulink ${ }^{\mathrm{TM}}$ and is parameterized to represent a vehicle simulator in order to analyse the effect of integrating the on-board hydrogen production mechanism.

\section{System Simulation and Results}

The simulation parameters are gathered from varies sources such as [12], [15]. For illustrative purposes, example simulation results are shown here. For this simulation the following parameters were used; $m_{s}=335 \mathrm{~kg}$ for initial and $m_{s}=464 \mathrm{~kg}$ for fully loaded condition. $m_{u}=35 \mathrm{~kg}, k_{s}=16812 \mathrm{Nm}^{-1}, k_{t}=190000 \mathrm{Nm}^{-1}$, $b_{s}=1000 \mathrm{Nm}^{-1}$ and $b_{t}=1000 \mathrm{Nm}^{-1}$. Figure. 9 shows the instantaneous force from the active suspension. This simulation was carried out with an assumption that the road disturbance is a $5 \mathrm{~mm}$ sine wave with a frequency of $10 \mathrm{~Hz}$. It should be noted that the negative values in Figure.9 means that the active force is against the movement of the suspension and indicates that it allows some power recovery. It can also be seen that the heavier the car, the less force required for the active suspension. The peak instantaneous power for different disturbance frequency and magnitude is shown in Figures 10 and 11. The energy recovered will be fed to the electrolyser for hydrogen production. Hydrogen production rates for disturbance at $5 \mathrm{~mm}$ magnitude with different frequencies are shown in Figures 12 and 13 for initial and fully loaded conditions respectively. From the results it can be seen that significant amount of hydrogen can be produced using this suspension energy recovery mechanism. It can be seen that the dominant feature of the hydrogen production is the frequency or the magnitude of the disturbance instead of the weight of the vehicle.

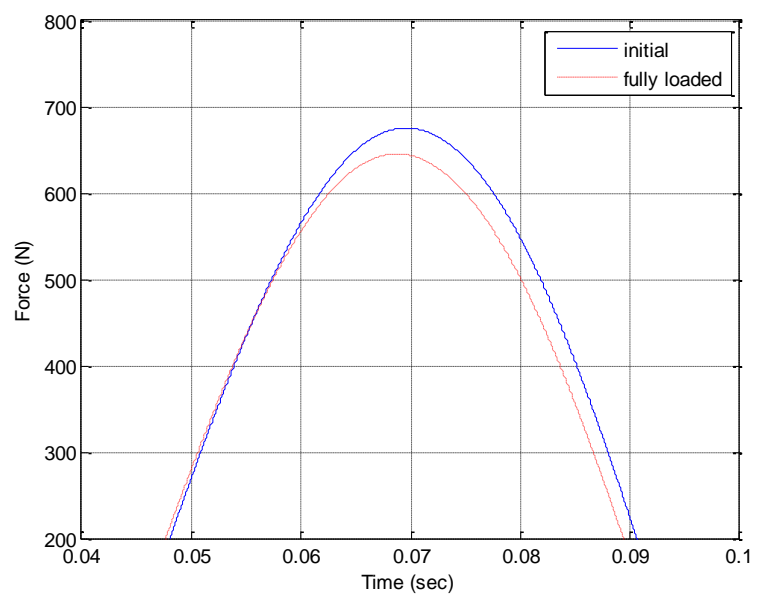

Fig. 9 Active suspension instantaneous force

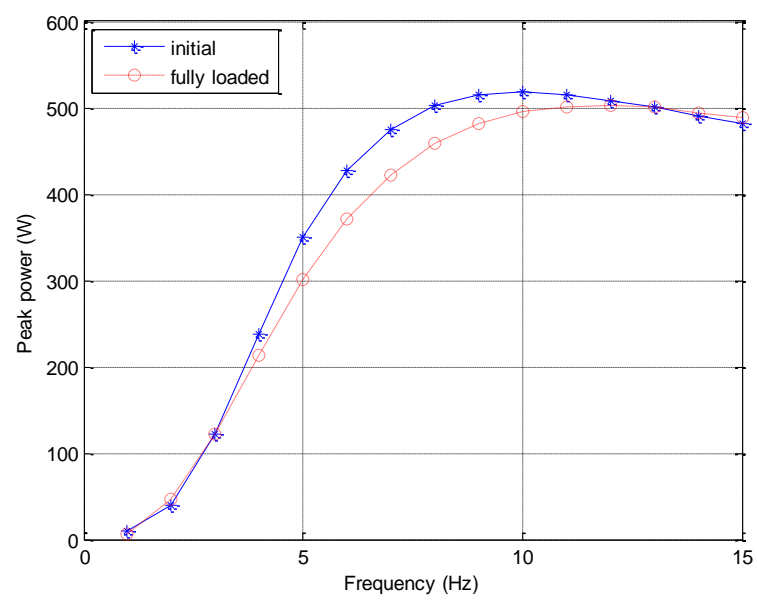

Fig. 10 Active suspension peak power for different frequency of the disturbance

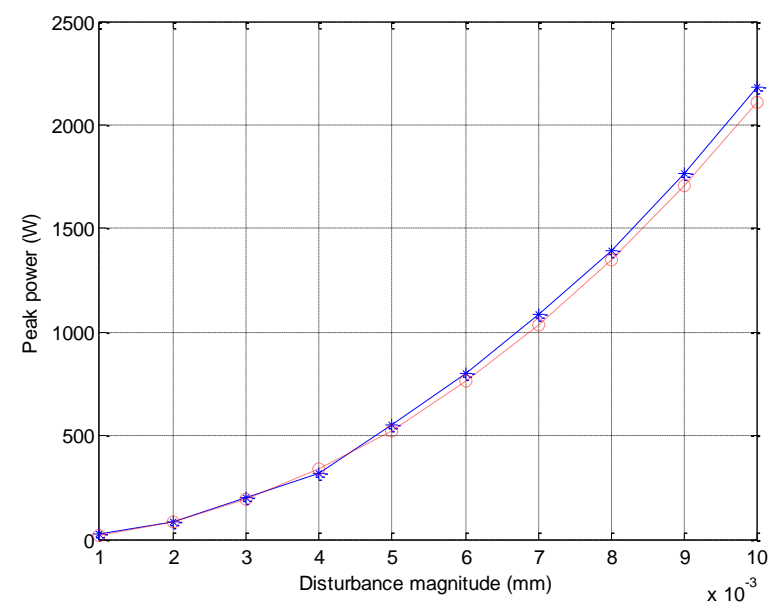

Fig. 11 Active suspension peak power for different magnitude of the disturbance 


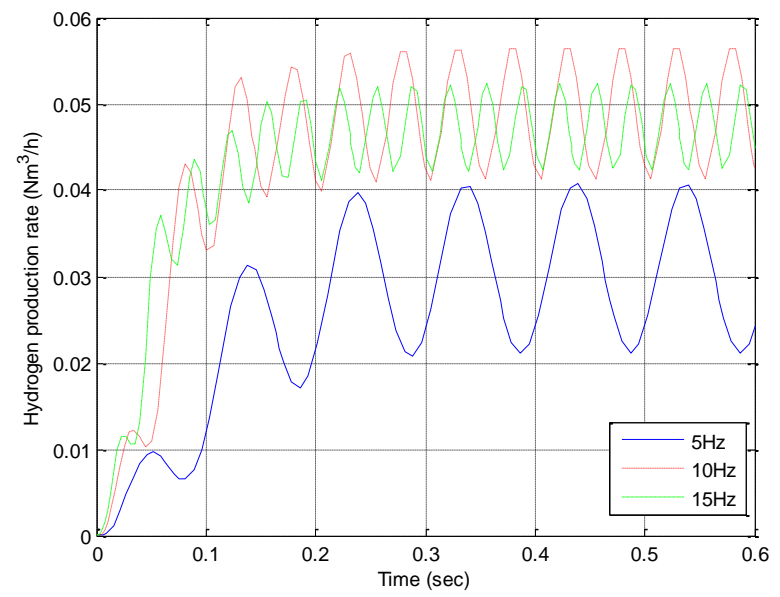

Fig. 12 Hydrogen production rate for disturbance at $5 \mathrm{~mm}$ magnitude with different frequency (initial car condition)

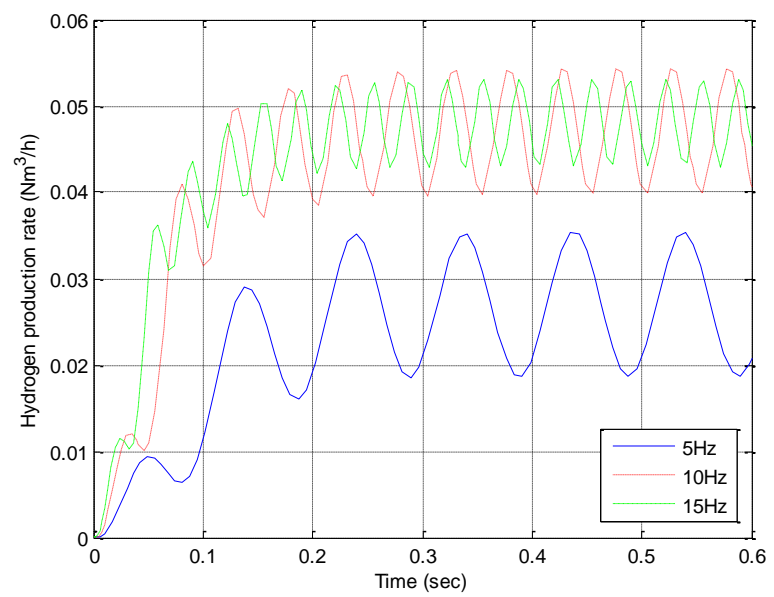

Fig. 13 Hydrogen production rate for disturbance at $5 \mathrm{~mm}$ magnitude with different frequency (fully loaded condition)

\section{Concluding Remarks}

This paper is focused on energy saving mechanisms for hydrogen based vehicles. In particular the development of an on-board $\mathrm{H}_{2}$ production and storage system is discussed in detail. Analysis for better energy management strategies are carried out via simulation studies by using the simulation tools developed by the UoG. Simulation results indicate that the energy consumption can be reduced by incorporating the onboard $\mathrm{H}_{2}$ production and storage system and energy can be recovered at appreciable rates and hence can contribute additional hydrogen to that stored on-board.

\section{Acknowledgement}

The work presented in this paper has been supported in part by the Wales Assembly Government, UK, under ERDF-Cymru H2 Wales project.

\section{References}

[1] Zamora I, San Martin JI, Garcia J, Asensio FJ, Onederra $\mathrm{O}$, San Martin JJ, Aperribay V. "PEM Fuel Cells in Applications of Urban Public Transport". Renew Energ Power Qual J 2011; 9: 399.

[2] Thanapalan KKT, Williams JG, Premier GC, Guwy AJ. "Design and Implementation of Renewable Hydrogen Fuel Cell Vehicles". Renew Energ Power Qual J 2011; 9: 310

[3] Hernandez F, Rodriguez C, Hernandez JL, "Critical analysis on hydrogen as an alternative to fossil fuels and biofuels for vehicles in Europe", Renewable and Sustainable Energy Reviews, Vol.14, pp772-780, 2010

[4] Andreasen SJ, Ashworth L, Natanael I, Remon M, Kaer SK., " Directly connected series coupled HTPEM fuel cell stacks to a Li-ion battery DC bus for a fuel cell electrical vehicle", International Journal of Hydrogen Energy, Vol.33, pp7137-7145, 2008

[5] Burke AF, "Electrochemical Capacitors for Electric Vehicles: Technology update and Implementation Considerations", In the Proc of $14^{\text {th }}$ Electric Vehicle Symposium, pp.27-36, 1996

[6] Schupbach R, Balda J, Zolot M, Kramer B, “ Design methodology of a combined battery-ultracapacitor energy storage unit for vehicle power management", In the Proc of 2003 IEEE Power Electronics Specialist Conference, Acapulco, 2003, pp88-93

[7] Mackenzie W, "Energy production and consumption" 2004 (www.woodmac.com)

[8] UNFCC green house gas inventory report, 2009

[9] Hawkes FR, Hussy I, Kyazze G, Dinsdale R, Hawkes DL. Continuous dark fermentative hydrogen production by mesophilic microflora: Principles and progress. Int $\mathrm{J}$ Hydrogen Energy, 2007, vo.1.32: pp.172-184.

[10] Thanapalan KKT, Wang B, Williams JG, Liu GP, Rees D. "Modelling, Parameter Estimation and Validation of a 300W PEM Fuel Cell System". In the Proc. of UKACC, Int. Conf. on Control, Manchester, UK, 2008.

[11] Rajamani R, Hedrick KJ. "Adaptive observers for active automotive suspensions theory and experiment". IEEE Transactions on control systems technology, 1995, vol.3, No.1

[12] Martins I, Esteves M, Pina da Silva F, Verdelho P. “ Electromagnetic hybrid active-passive vehicle suspension system "In the Proc. of 49th IEEE Vehicular Technology Conference, 1999, pp2273-2277.

[13] Gorgun H. "Dynamic modeling of a proton exchange membrane (PEM) electrolyzer". Journal of Hydrogen Energy, 2006, vol.31, pp.29-38

[14] Ulleberg $\varnothing$. "Modeling of advanced alkaline electrolysers: a system simulation approach" International Journal of Hydrogen Energy, 2003, vol. 28, pp. 21-33.

[15] Rao MVC, Prahlad V. "A tunable fuzzy logic controller for vehicle-active suspension systems". Fuzzy Sets and Systems, 1997, vol. 85, pp11-21 